\title{
EU Emissions Trading Scheme as Implemented in the Czech Republic
}

T. Chmelík, P. Zámyslický

\begin{abstract}
The paper reports on the implementation of the European Emissions Trading Scheme (EU ETS) in the Czech Republic. Trading in CO 2 emission allowances is one of the most dynamic and progressive economic instruments of environmental policy. Since coming into force in January 2005, the system has incorporated into company decision making a truly new phenomenon - the price of carbon in the form of allowances tradable on the European market, where the price of the allowance represents the costs of a company when emitting one ton of $\mathrm{CO}_{2}$. The incentive, given by the opportunity costs should motivate operators of installations emitting $\mathrm{CO}_{2}$ to analyze options for carbon emission reduction and to behave rationally. In total, the system should result in a quite significant reduction in the compliance costs of $\mathrm{CO}_{2}$ reduction when compared to alternatives such as taxes or emission limits, as a result of flexibility given by the market.

The most controversial and sensitive part of the system is the initial distribution of the allowances to emitters. The so-called National Allocation Plan has to provide answers to very difficult questions - to whom, how and how many allowances will be given. This paper focuses on a detailed description of the sectors and companies in the Czech Republic that are affected by the system and discusses various aspects of the scheme.
\end{abstract}

Keywords: EU Emissions Trading Scheme (EU ETS), National Allocation Plan (NAP), allowances, industry.

\section{What is EU ETS?}

The EU Emissions Trading Scheme (EU ETS) has been developed by the EU to serve as one of the main instruments of the European Community to achieve its reduction targets, as agreed in the Kyoto Protocol to the United Nations Framework Convention on Climate Change. In this protocol, a group of industrialized countries agreed to take on concrete targets to reduce emissions of greenhouse gases to support the main objective of the Convention - to stabilize the concentrations of greenhouse gases in the atmosphere and limit anthropogenic (human related) influences on the global climate system.

The European Union as one of the signatories agreed to reduce its emissions in the so-called commitment period (2008-2012) by $8 \%$ compared to 1990 . To achieve this target various policies and measures have been and have yet to be, implemented. Industry is one of the key sectors emitting greenhouse gases, and an important question was which instrument to use. Based on experience of the USA with sulphur dioxide $\left(\mathrm{SO}_{2}\right)$ emissions trading, a $\mathrm{CO}_{2}$ trading system was developed to cover all (EU-25) countries. This started with the shorter pre-commitment period phase (2005-2007) and will continue with five-year trading phases as of 2008. The system is based on the following five pillars:

- Allocation (a system of distribution of emission allowances to participants, based on harmonized criteria).

- Registration (each industrial participant has to operate on the basis of a permit defining conditions for its operation and monitoring of emissions).

- Monitoring (a harmonized system of monitoring of emissions focusing on accuracy and quality of data).

- Reporting (companies are obliged to annually monitor emissions of $\mathrm{CO}_{2}$ and surrender allowances equal to emissions).

- Verification (emissions are independently verified).

Trading with allowances across the EU is not further limited. Not only emitters, but also other participants can trade (such as brokers and investors) to help market liquidity.

\section{Czech National Allocation Plan}

The National Allocation Plan (NAP) is a key element of the whole trading system. On the basis of legislative criteria it has to include certain types of emission sources (called installations) that emit carbon dioxide $\left(\mathrm{CO}_{2}\right)$. The EU system defines the criteria for obligatory participation in the system for key sectors (energy production, refineries, production and processing of metals, the mineral industry (ceramics, glass, cement, lime), pulp and paper). The key element of the allocation plan is that decisions on allocations must be made before the trading period begins and ex-post adjustments are not allowed. This provides investment certainty for participants.

Allowances are distributed to operators free of charge (a voluntary auction of small amounts of allowances is allowed). NAP therefore represents mainly a distributional challenge. The allocation has to be based on non-discriminatory and fair criteria, both on a national and on an individual level, NAP is also screened against state aid rules. Each allocation plan has to pass a scrutiny assessment by the European Commission, which will assess whether the NAP fulfills all the criteria as listed in the legislation. The Czech allocation plan has been approved, and 97.6 million allowances are to be distributed among more than 400 participants each year in the period 2005-2007. The allocations in the Czech Allocation Plan are based on a mathematical formula using historical emissions of installations, adjusted to reflect some specific elements (combined heat and power production, centralized heating systems, early action, etc.).

\subsection{Sectoral coverage}

A simple comparison shows that some sectors, while having almost the same number of installations, have a much smaller share of total emissions. This indicates that some criteria in the system do not reflect the real emissions, but rather the installed capacity. Therefore the system covers a number of small installations in terms of their annual emissions, and for these installations the system could represent more of a 
Table 1: NAP for the Czech Republic, by sector

\begin{tabular}{|l|c|c|}
\hline & Share of total emissions & Number of installations \\
\hline Public energy production (Utilities) & $66.59 \%$ & 139 \\
\hline Corporate energy production & $3.53 \%$ & 135 \\
\hline Refineries & $1.10 \%$ & 4 \\
\hline Chemicals & $5.28 \%$ & 17 \\
\hline Coke & $0.26 \%$ & 2 \\
\hline Production and processing of metals & $16.22 \%$ & 19 \\
\hline Cement & $2.95 \%$ & 6 \\
\hline Lime & $1.34 \%$ & 5 \\
\hline Glass & $0.84 \%$ & 21 \\
\hline Ceramics & $0.78 \%$ & 60 \\
\hline Pulp & $0.19 \%$ & 2 \\
\hline Paper and board & $0.91 \%$ & 16 \\
\hline Total & & $\mathbf{4 2 6}$ \\
\hline
\end{tabular}

Source: Ministry of the Environment, 2005

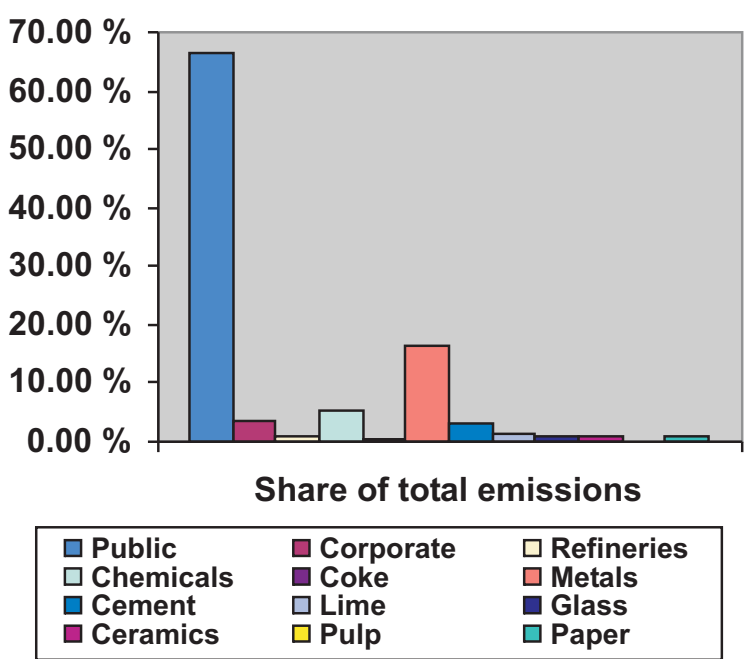

Fig. 1: Share of total emissions, by sector

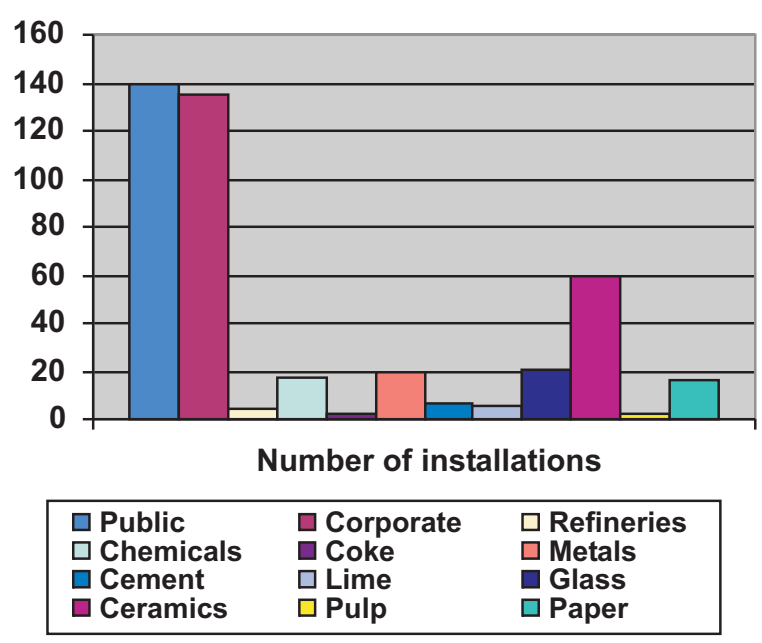

Fig. 2: Number of installations, by sector burden than an opportunity, also. In addition, the real impact of these small companies (their share of national emissions is almost negligible) is disputable. This is particularly visible in the Czech energy sector - public energy production (including all large powerplants that supply power to the national grid) and corporate energy production.

This effect can be further demonstrated in a graph of cumulative allocation (as allocation is based on historical data, the graph would look almost the same if historic emissions were used). The vast majority of these installations contribute only a small percentage of the total emissions (allocation).

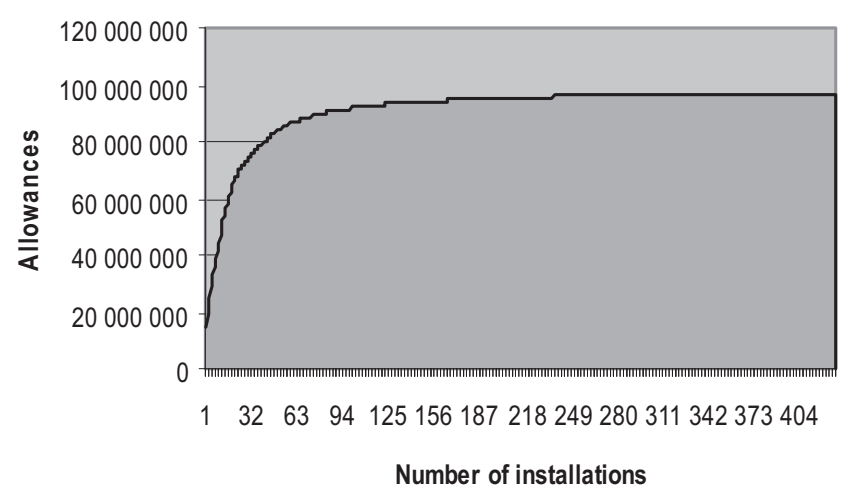

Fig. 3: Cumulative allocation

\subsection{Selected participants}

A closer look at company level allocation yields the following observations.

Eleven of the fifteen installations are from the energy production sector, and eight of them are owned by a single company, ČEZ, which is by far the biggest player on the Czech allowance market. These 15 companies have an allocation of 56.5 million allowances (almost $58 \%$ of the total allocation). 


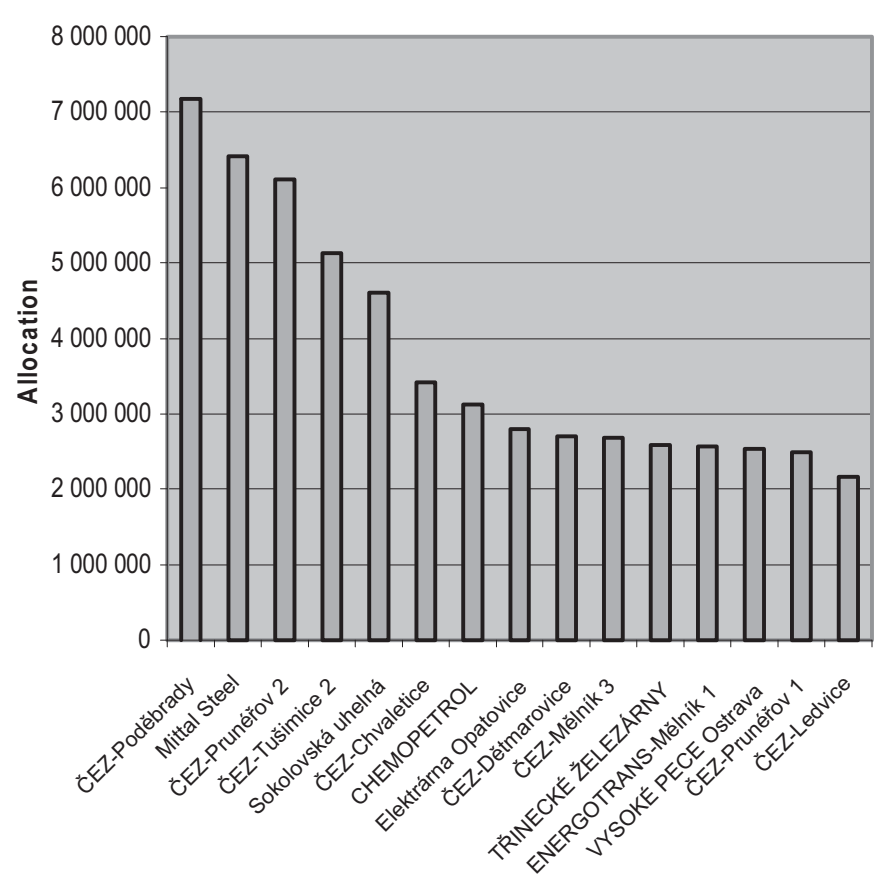

Fig. 4: Allocation (amount of allowances) to selected installations

An interesting point is that with the planned acquisition of Mittal Steel and Vysoké Pece Ostrava under a single company, the biggest installation will not be an energy company, but a company from the metal sector. However, the public energy production will remain the key sector from the allowance point of view.

\section{Conclusions}

The simple survey made in this paper indicates that the EU ETS system in the Czech Republic covers installations varying in size from several millions of allowances annually to several hundreds of allowances annually. While the number of participants in the system (around 12000 throughout EU-25) clearly helps liquidity on the market and can bring opportunities in variability of abatement costs, the administrative burden of the scheme must also be taken into account. This involves not only the size of the scheme and the burden related to government "management" of the system, but also the burden on companies themselves (costs related to participation, monitoring, verification of data, etc.) The inclusion of sectors such as ceramics and glass is in particular questionable, because in these two sectors (together with corporate energy production) most installations emit only small amounts of $\mathrm{CO}_{2}$.

One issue that is discussed on the European level is the inclusion of a minimum threshold on emissions, so that obligatory inclusion in the scheme would be based on fulfillment not only of technical criteria (e.g. installed capacity), but also on the level of emissions in past years. This could significantly reduce the number of installations covered and probably without a major impact on the scope of trading. However, such adjustments cannot be made without broader consensus across EU-25 and without changes to the legislation. It is planned to consider these ideas within a revision of the system that is planned to begin in the second half of 2006 .

\section{Acknowledgments}

The study described in this paper was supervised by Jaroslav Knapek.

\section{References}

National Allocation Plan of the Czech Republic 2005 to 2007, Ministry of Environment of the Czech Republic, September 2005 .

Ing. Tomáš Chmelík

e-mail: Tomas_Chmelik@env.cz

Ing. Pavel Zámyslický

e-mail: Pavel_Zamyslicky@env.c

Dept. of Economics, Management and Humanities

Czech Technical University in Prague

Faculty of Electrical Engineering

Technická 2

16627 Praha, Czech Republic 